\title{
Pharmacists' expectations regarding the services provided by drug and poison information center
}

\author{
Somayeh Hanafi, Mirhamed Hajimiri, Hassan Torkamandi, Alireza Hayatshahi and \\ Mohammad Reza Javadi*
}

Department of Pharmaceutical Care, Dr.Shariati Hospital, Jalal-e-Al-e Ahmad, Tehran, Iran.

Accepted 28 November, 2011

\begin{abstract}
Health care professionals have been surveyed concerning their satisfaction with Drug and Poison Information Centers' (DPICs) services, but have rarely been questioned regarding their expectations. Knowing these expectations would be the starting point for improvement of DPIC's services. As pharmacists are a major group of DPICs' clients, this study was aimed to clarify the expectations of Iranian pharmacists regarding the services provided by the DPIC in Tehran University of Medical Sciences. Data was collected from questionnaire which was distributed among 562 pharmacists in August, 2008. Data was analyzed by producing descriptive statistics using Statistical Package for Social Sciences (SPSS) software (version 17). The mean importance rating for each expectation was determined and sorted in descending order. A response rate of $87.9 \%$ was achieved. Drug information textbooks and medical reference books were the 'most commonly used' drug information resources. Thirty six expectations had a mean importance rating of $\geq 3$ ( $3=$ important). Currently, there is a good fit between Iranian pharmacists' expectations and DPIC services provided. This survey identified several areas where services was expected but not provided (e.g. provision of telephone consultation services $24 \mathrm{~h}$ a day). In instances, where there was a gap between expectations and services provided, the DPIC made programmatic changes to align service with expectation when feasible.
\end{abstract}

Key words: Drug and poison information center (DPIC), pharmacists, expectations.

\section{INTRODUCTION}

A Drug and Poison Information Center (DPIC) is a formal unit with a series of resources and a professionally trained team engaged in providing accurate and factual information about drugs and poisons (Hall et al., 2006; George and Rao, 2005). World's DPICs are mainly affiliated to hospitals, faculties of pharmacy, faculties of medicine and other related organizations (Mullerova and Vlcek, 1998). The provision of accurate, prompt, timely and evidence-based drug and poison information to health care professionals is an important mechanism to promote safe and effective drug therapy for patients (Lakshmi etal., 2003; Ngo Su-Yin and Ponampalam, 2009). The complexity of the current drug literature has made the selection and use of correct drugs in an appropriate manner, a challenging task (Asiri et al.,2007). Lack of unbiased drug information is one of the factors that make the health care providers unable to update their knowledge about drugs which results in an increasing demand for drug information to promote patient care. Therefore, DPICs' services are necessary to provide support for health care providers (George and Rao, 2005; Wongpoowarak et al., 2010; Rosenberg, 1983).

The first drug information center (DIC), was established in 1962 at the University of Kentucky. Since then, DICs have expanded outside academic settings to include hospitals and pharmaceutical industry (Dada et

*Corresponding author. E-mail: mrjavadi@sina.tums.ac.ir. Tel: +982184902364. 
Table 1. Demographic variables of survey respondents.

\begin{tabular}{llc}
\hline Demographic variable & & Frequency $\mathbf{n}(\%)$ \\
\hline \multirow{2}{*}{ Gender } & Male & $201(40.6)$ \\
& Female & $291(58.8)$ \\
& $<5$ & $129(26.1)$ \\
Pharmacy practice experience (years) & Between 5-10 & $86(17.4)$ \\
& Between 10-15 & $108(21.8)$ \\
& $>15$ & $162(32.7)$ \\
& & \\
& Hospital pharmacy & $49(9.9)$ \\
Practice field & Community Pharmacy & $353(71.3)$ \\
& Pharmaceutical Industry & $32(6.5)$ \\
Being familiar with DPICs' activities & Others & $47(9.5)$ \\
and services & Yes & $224(45.3)$ \\
& No & $228(46.1)$ \\
Estimated number of contacts & No contact & $373(75.4)$ \\
with DPICs during last month & $<5$ & $60(12.1)$ \\
& $<10$ & $8(1.6)$ \\
& $>10$ & $5(1.0)$ \\
\hline
\end{tabular}

al., 2008). Iran's first DPIC was opened in Tehran Ministry of Health, Under-secretary of Food and Drugs in February, 1997 with the intention of providing a centralized resource center for drug and poison emergency treatment advice and information to healthcare professionals, industries and general public (Nikfar et al., 2000). Health care professionals have been surveyed concerning their satisfaction with DPICs services, but have rarely been questioned regarding their expectations (Rheney et al., 2000). As the health care providers expect guidance and expert advice from DPICs', knowing client's expectations would be the starting point for improvement of DPICs' services (Scala et al., 2001). Pharmacists are one large group of DPICs' clients. This study was conducted to clarify the expectations of Iranian pharmacists regarding the services provided by the DPIC in Tehran University of Medical Sciences which was established in 2007.

\section{METHODOLOGY}

The study was descriptive. A questionnaire was prepared to investigate the pharmacists' expectations about DPICs. We invited all 562 pharmacists in Iranian Pharmacists Association Annual Congress which was held in August 2008 to participate in this survey.

A cover, describing the world's DPICs background and activities was attached to the questionnaire. The names of the respondents were not requested to maintain anonymity. Questions in this study covered a number of areas as follows:

1. The first section included the survey population demographic information including age, sex, professional or educational qualifications, university degree and job experience.

2. The current sources of drug and poison information being utilized by respondents were elicited from a list of suggested options (drug and poison information centers, textbooks, software's, journals and websites and colleagues) and the frequency of the sources usage was ranked to the following three levels: almost never, occasionally and frequently.

3. Thirty seven expectations were developed in five choices LikertScale. Survey instructions directed the respondents to rank the importance of each expectation on a scale of 1 to 5 , where $1=$ not important, 2 = somewhat important, $3=$ important, $4=$ very important and $5=$ extremely important.

\section{Statistical analysis}

The filled questionnaires were analyzed by producing descriptive analysis using the Statistical Package for Social Sciences (SPSS for MS windows version 17). The mean importance rating for each expectation was determined and sorted in descending order.

\section{RESULTS}

\section{Demographics}

Out of the 562 potential responders who received the questionnaires, 494 fulfilled them, giving a response rate around eighty eight percent $(87.9 \%)$. The average age of the respondents was around 41 years $(41.49 \pm 12.61)$. $95.1 \%$ of the pharmacists surveyed had a PharmD degree. The demographics of the responders are summarized in Table 1 (Note that the percentages through 
Table 2. Frequency of using each source of drug information.

\begin{tabular}{lc}
\hline Variable & Frequency (\%) \\
\hline Using DPICs & \\
Almost never & $175(35.4)$ \\
Occasionally & $176(35.6)$ \\
Frequently & $16(3.2)$ \\
& \\
Using drug information textbooks and medical reference books & \\
Almost never & $23(4.6)$ \\
Occasionally & $157(31.7)$ \\
Frequently & $250(50.5)$ \\
& \\
Using drug information software's & \\
Almost never & $94(19.0)$ \\
Occasionally & $179(36.2)$ \\
Frequently & $75(15.2)$ \\
& \\
Using medical and pharmaceutical journals & \\
Almost never & $36(7.3)$ \\
Occasionally & $232(46.9)$ \\
Frequently & $147(29.7)$ \\
Using drug information websites & \\
Almost never & \\
Occasionally & $84(17.0)$ \\
Frequently & $180(36.4)$ \\
Consulting expert colleagues & $98(19.8)$ \\
Almost never & \\
Occasionally & \\
Frequently & $42(8.5)$ \\
\hline & $230(46.5)$ \\
& $109(22.0)$ \\
\hline
\end{tabular}

this manuscript are all computed considering the number of missing cases in questionnaires).

The main resources used by responders for drug information are listed in Table 2. Tertiary sources, such as 'drug information textbooks and medical reference books' followed by 'medical and pharmaceutical journals and 'expert colleagues' formed the large bulk of the frequently used drug information resources for answering the queries (Table 2).

There were 36 expectations included on the survey instrument. Expectations are presented in the order of descending mean importance rating in Table 3 . Thirty six $(97 \%)$ survey expectations had a mean importance rating of $\geq 3$ ( $3=$ important). 'The provision of new drug information' and 'the provision of information on radiopharmaceutical and chemotherapeutic drugs preparations' had the most and the least importance ratings among all expectations, respectively.

The respondents' acquaintance with the DPIC's services and their future approach to make phone calls with these centers are summarized in Table 4.

\section{DISCUSSION}

DPICs are established with the primary goal of providing information to health care providers in need of medication-related issues (Sawalha, 2008). Expectation surveys are being used to improve the match between services provided and the client expectations (Karen et al., 2000). Comprehensive reviews of DPICs' services have been reported, but relatively little is known of the expectations of health care professionals regarding the services of these centers. We surveyed pharmacists, because they frequently use the services of the DPICs, so, constituting the major class enquirers for these centers.

Our survey data indicate that there is a good match between our pharmacists' expectations and services provided by DPIC. Most of the expectations with the highest importance ratings are the center's basic functions, like 'provision of new drug information', 'provision of drug use during pregnancy information' and 'provision of drug-drug and drug-food interaction information'. Similar to our 
Table 3. Importance ratings for pharmacists' expectations.

\begin{tabular}{|c|c|c|}
\hline Expectation & $\begin{array}{l}\text { Mean } \\
\text { rating }\end{array}$ & $\begin{array}{l}\text { Standard } \\
\text { deviation }\end{array}$ \\
\hline Provide new drug information & 4.31 & 0.89 \\
\hline Provide telephone consultation services 24 hours a day & 4.13 & 0.95 \\
\hline Provide drug use during pregnancy information & 4.08 & 0.93 \\
\hline Provide drug-drug and drug-food interaction information & 4.06 & 0.90 \\
\hline Provide pediatric drug dosing information & 3.96 & 1.00 \\
\hline Provide continuing education courses about drug information for health care professionals & 3.94 & 0.95 \\
\hline Provide drug use during lactation information & 3.89 & 0.99 \\
\hline Provide treatment information for toxic ingestions & 3.82 & 0.97 \\
\hline Provide information on drugs' adverse drug reactions & 3.78 & 0.98 \\
\hline Provide foreign drug identification & 3.73 & 1.02 \\
\hline Provide drug dosing information & 3.65 & 1.04 \\
\hline Provide cleaning substances hazards information & 3.62 & 1.04 \\
\hline $\begin{array}{l}\text { Provide other referral services (i.e., if the center does not have the information, refer the caller } \\
\text { to where the information is available) }\end{array}$ & 3.60 & 0.98 \\
\hline Provide consultation for health-care providers regarding poisoning & 3.54 & 1.02 \\
\hline Provide clinical signs and symptoms information regarding toxic ingestions & 3.50 & 1.03 \\
\hline Provide pesticides hazard information & 3.49 & 1.04 \\
\hline Provide carbon monoxide hazards information & 3.47 & 1.07 \\
\hline Provide drug storage condition information & 3.44 & 1.03 \\
\hline Provide smoke inhalation hazards information & 3.44 & 1.03 \\
\hline Provide drug dosing information in special patients & 3.41 & 1.11 \\
\hline Research information from manufacturers for various products & 3.41 & 1.03 \\
\hline Education/ training of center's health care professionals & 3.39 & 1.03 \\
\hline Provide patient-specific recommendations in electronic/ written format & 3.37 & 1.44 \\
\hline Provide printed material from our library of information including fax services & 3.37 & 1.08 \\
\hline Provide insect stings hazards information & 3.35 & 1.01 \\
\hline $\begin{array}{l}\text { Collect and provide demographic/epidemiology information (e.g., regarding poisonings, trends } \\
\text { in overdoses of street drugs) }\end{array}$ & 3.34 & 1.01 \\
\hline Referral of the general public to physician when needed & 3.32 & 0.99 \\
\hline Provide education of the general public regarding poisoning & 3.32 & 0.99 \\
\hline Provide dietary supplement information & 3.30 & 2.23 \\
\hline Provide chemical spills and industrial exposures hazards information & 3.30 & 1.08 \\
\hline Identify ingredients of brand-name products & 3.21 & 1.06 \\
\hline Provide information on herbal drugs & 3.14 & 1.07 \\
\hline Provide green chile dermal exposure hazards information & 3.12 & 1.05 \\
\hline Provide rattlesnake bites hazards information & 3.11 & 1.13 \\
\hline Provide identification of tablets or capsules & 3.06 & 1.04 \\
\hline Provide information on radiopharmaceutical and chemotherapeutic drugs preparations & 2.88 & 1.19 \\
\hline
\end{tabular}

Table 4. Pharmacists' future approach towards using DPICs.

\begin{tabular}{lc}
\hline Future approach & Frequency (\%) \\
\hline Previous acquaintance/Future phone calls & $225(45.5)$ \\
Previous acquaintance/No future phone calls & $2(0.4)$ \\
No Previous acquaintance/Future phone calls & $161(32.6)$ \\
No Previous acquaintance/ No future phone calls & $1(0.2)$ \\
\hline
\end{tabular}


findings, $69 \%$ of the respondents in a study by Rosenberg et al. (2009) indicated that the primary mission of the drug information centers is 'the provision of not-for-profit new drug information services'. In addition, the most frequent type of inquiries in a drug information center at the University of Kansas Medical Center involves information on these subjects: therapeutic use, dosage, product identification and adverse drug reactions (Pradhan, 2002). Also, the majority of inquiries which are most frequently asked in Food and Drug Administration (FDA) DPIC are related to 'investigational new drugs' and 'adverse drug reactions' (Dada et al., 2008).

According to our results, the service with the lowest importance ratings centered on the 'provision of information on radiopharmaceutical and chemotherapeutic drugs preparations'. This view was reinforced in a study by Karen et al. (2000) where 'provision of radiopharmaceutical drug information' was the expectation with the lowest importance rating (Sawalha, 2008). Although, there is a possible reason for this service's low importance rating (the respondent may not see a true need for the service as it relates to their practice), it would be better to ask this question in a way that health care providers who are directly involved in radiopharmaceutical and chemotherapeutic drugs preparations, could provide a separate rating for this expectation.

Using a stepwise approach, most drug information searches should begin by using tertiary literature (e.g. reference books, Micromedex Healthcare Series), followed by secondary indexing and abstracting data-bases (e.g. Medline) leading to primary literature (e.g. journal articles) when necessary (Nathan and Gim, 2009). The results of our study showed that the main drug information resources used frequently by the pharmacists for answering the patients queries are tertiary sources, such as 'drug information textbooks and medical reference books' followed by 'medical and pharmaceutical journals' and 'expert colleagues'. Similar findings were made in a study done in Singapore, assessing the need for drug and poison information, where the most used resources were 'standard text books' followed by 'expert colleagues' (Ponampalam and Anantharaman, 2003). In a paper by Rheney et al. (2000), North Carolina health care providers rarely use DPICs as sources of drug information. This was reinforced in our study, where $35.4 \%$ of the respondents almost never use this kind of drug information service. Being non acquaintance with existence of such centers and their services would be considered as the most important reason of not using them as sources of drug information. Even after 13 years of opening of the first DPIC in Iran, the health care professionals are not familiar with these centers' unique activities yet.

Expectations having a mean importance rating of $\geq 3$ ( 3 = important) were reviewed to determine whether the service was currently provided. After reviewing the results, we began to develop active steps to bring the center's services closer in line with pharmacists' expectations. For expectations. For instance, as the 'provision of continuing education courses regarding drug information' had a high importance rating (3.94), we began to provide this service in our center. Pharmacists now regularly participate in our DPIC's continuing education sessions.

\section{Conclusion}

Conclusively, identifying pharmacists' expectations regarding DPIC services would be the starting point for its services improvement. At present, there is a good fit between pharmacists' expectations and DPIC services currently provided. In instances, where there was a gap between expectations and services provided, the DPIC made programmatic changes to align service with expectation when feasible.

\section{ACKNOWLEDGEMENT}

The authors wish to acknowledge Tehran University of Medical Sciences for supporting this research by its grant.

\section{REFERENCES}

Hall V, Gomez C, Fernandez-Llimos F (2006). Situation of drug information centers and services in Costa Rica. Pharmacy. Practice. 4(2): 83-87.

George B, Rao PG (2005). Assessment and evaluation of drug information services provided in a south Indian teaching hospital. Indian. J. Pharmacol., 37(5): 315-318.

Mullerova H, Vlcek J (1998). European drug information centers- survey of activities. Pharm. World. Sci., 20 (3): 131-135.

Lakshmi PK, Gundu Rao DA, Gore SB, Bhaskaran S (2003). Drug Information Services to Doctors of Karnataka, India. Indian. J. Pharmacol. 35:245- 247.

Ngo Su-Yin A, Ponampalam R (2009). Singapore drug and poison information service: user satisfaction after three years. S.G.H. 18(1): 12-16.

Asiri YA, Al-Arifi MN, Al-Sultan MS, et al (2007). Evaluation of drug and poison information center in Saudi Arabia during the period 20002002. Saudi. Med. J., 28(4): 477-479.

Wongpoowarak $\mathrm{P}$, Phengchuai $\mathrm{C}$, Rattanachamit $\mathrm{P}$, Kaewmanee M, Konsuparp S, Wongpoowarak W, Boonme P (2010). Evaluation of drug information service via http://drug.pharmacy.psu.ac.th. Silpakorn Univ. Sci. Technol. J. 4(1):8-14.

Rosenberg JM (1983). Drug information centers future trends. Am. J. Hosp. Pharm., 40: 1213-1215.

Dada KC, Kremzner ME, Bhanot SK, Lal R (2008). Role of FDA's drug information centers. Am. J. Health Syst. Pharm. 65:803-805.

Nikfar S, Abdollahi M, Chraghali A (2000). Going from strength to strength- Iran's Drug and Poison Information Service. Essent. Drugs Monitor. 28, 29:30-31

Rheney CC, Byerly WG, Connelly JF (2000). North Carolina physician access to drug information resources. Drug Inform. J. 34 (1): 69-73.

Scala D, Bracco A, Cozzolino S, Cristinziano A, De Marino C, Di Martino A, Gonzalaez E., Mancini A, Romagnuolo F, Zeuli L (2001). Italian drug information centers: benchmark report. Pharm. World Sci. 23(6):217-223.

Sawalha AF (2008). Poison control and the drug information center: the Palestinian experience. I.M.A.J. 10: 757-760.

Dominguez KD, Gupchup GV, Benson BE (2000). A Survey of the Expectations of New Mexico Emergency Physicians Regarding the 
Services of the New Mexico Poison and Drug Information Center. Clin. Toxicol. 38(3):309- 319.

Rosenberg JM, Schilit S, Nathan JP, Zerilli T Mcgu H (2009). Update on the status of 89 drug information centers in the United States. Am. J. Health Syst. Pharm. 66:1718-1721.

Pradhan SC (2002). The performance of drug information center at the University of Kansas Medical Center, Kansas City, USA- experienced and evaluations. Indian J. Pharmacol. 34:123-129.
Nathan JP, Gim S (2009). Responding to drug information requests. Am. J. Health-Syst. Pharm. 66:706-711.

Ponampalam R, Anantharaman V (2003). The Need for Drug and Poison Information- The Singapore Physicians' Perspective. Singapore Med. J. 44(5):231- 242. 